Review

Sitian Zang, Shijie Chang, M. Babar Shahzad, Xiaoting Sun, Xiran Jiang, and Huazhe Yang*

\title{
Ceramics-based Drug Delivery System: A Review and Outlook
}

https://doi.org/10.1515/rams-2019-0010

Received Apr 04, 2018; accepted Oct 04, 2018

\begin{abstract}
The drug delivery system (DDS) is a hot spot in the field of medicine due to their favorable characteristics, such as the realizability of targeted therapy, sustained and controlled release of drug. Ceramic materials have abundant desirable properties, such as simple preparation, adjustable size and structure, surface area to volume ratio, desirable stability under physiological conditions and excellent biocompatibility, etc. Hence they have been successfully applied in the field of DDS considerably in decades, acting as drug carriers. Traditional ceramic materials refer to inorganic solid compound. They are mainly composed of carbides, oxides such as hydroxyapatite, tricalcium phosphate, silica, zeolite, and zirconia, etc. This review summarized the applications of the ceramic materials in the field of DDS in recent years, meanwhile the outlooks of future development were also proposed.
\end{abstract}

\section{Introduction}

The drug delivery system (DDS) is the composite of drug and carrier where drugs are loaded inside or on the surface of the carriers through chemical or physical methods [1-4]. Drug carriers are classified in various types as shown in Figure 1. Size, structure and properties of carriers have effects on the loading capacity of drugs. Furthermore, the distribution and release rate of drug can be controlled, which is favorable for the accurate target and treatment of the lesion

\footnotetext{
*Corresponding Author: Huazhe Yang: Department of Biophysics, School of Fundamental Sciences, China Medical University, Shenyang 110122; Email: hzyang@cmu.edu.cn Sitian Zang: Department of Biophysics, School of Fundamental Sciences, China Medical University, Shenyang 110122

Shijie Chang, Xiran Jiang: Department of Biomedical Engineering, School of Fundamental Sciences, China Medical University, Shenyang 110122

M. Babar Shahzad: Institute of Metal Research, Chinese Academy of Sciences, Shenyang 110016, China

Xiaoting Sun: Department of Chemistry, School of Fundamental Sciences, China Medical University, Shenyang 110122
}

๑ Open Access. (C) 2019 S. Zang et al., published by De Gruyte (cc) BY License site [5-9]. Effective dose requirements (ED50) may also decrease because of high delivery efficiency of controlled, sustained and targeted DDS, which could help in cost reduction for patients. Especially, there is an increasing desire for local, homogeneous, controlled and sustained release of drug nowadays. Therefore, it is of great importance to prepare carriers with adjustable size and structure, desirable stability under physiological conditions, excellent biocompatibility and high uptake efficiency. From this perspective, ceramics are the desirable candidate material for carriers.

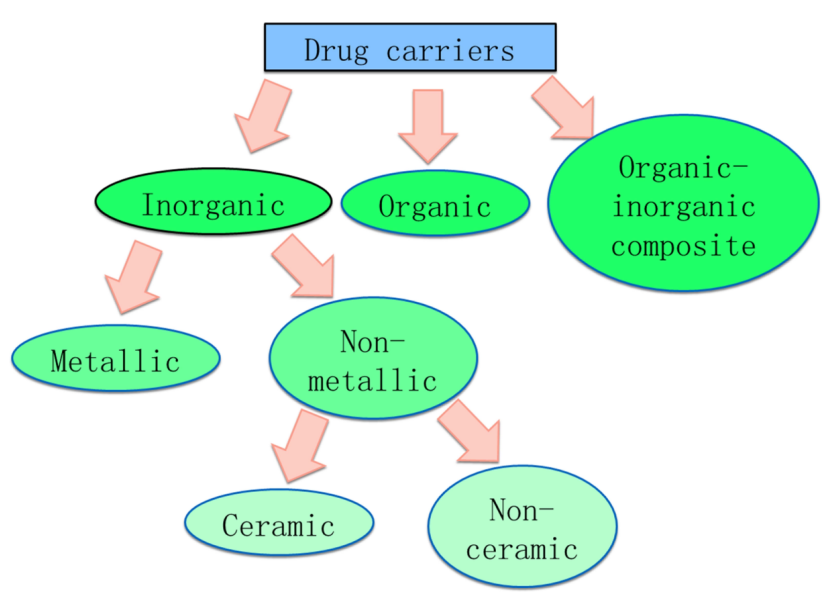

Figure 1: Classification of drug carriers

The ceramic-based drug carriers have attracted increasing attention with the developments in medicine, pharmaceutics, and material science. Popular bioceramics include: beta tricalcium phosphate ( $\beta$-TCP), hydroxyapatite, mesoporous silica, zirconia hydroxyapatite composite, etc. Meanwhile bioceramics are important parts of some inorganic-organic composites used as drug carriers.

The advantages of ceramic-based drug carriers are as follows: 1.Adjustable size and structure which are favorable for loading nano-sized drugs; 2.Low toxicity. Ceramics have good biocompatibility, biodegradability and biological stability; 3.Some ceramics are sensitive to environment, which can response to light, magnetism or heat, etc. These characteristics make them feasible for accurate targeted. Hence ceramic-based drug carriers have attracted 
great attention of investigators from the fields of biomaterial, biophysics, biochemistry, bioengineering, pharmaceutics and medicine. They mainly refer to hydroxyapatite, tricalcium phosphate, silica, zeolite, and zirconia, etc [10].

Bioceramics are considered as desirable drug reservoirs or matrix in DDS [11, 12]. The principle of drugloading for ceramic-based DDS is shown in Figure 2. For instance, $\beta$-TCP can be manufactured to hollow structure with certain shape and size. They can degrade gradually in physiological environment under the action of body fluids, enzyme or cell. Pharmaceutical diffusing out via pores of ceramics depends on the concentration gradient and drug solubility, and porosity of ceramics drug carrier influence the diffusion of drugs. Drugs can be loaded inside or on the surface of the carriers by various method such as facile sono-chemical method [13-15].

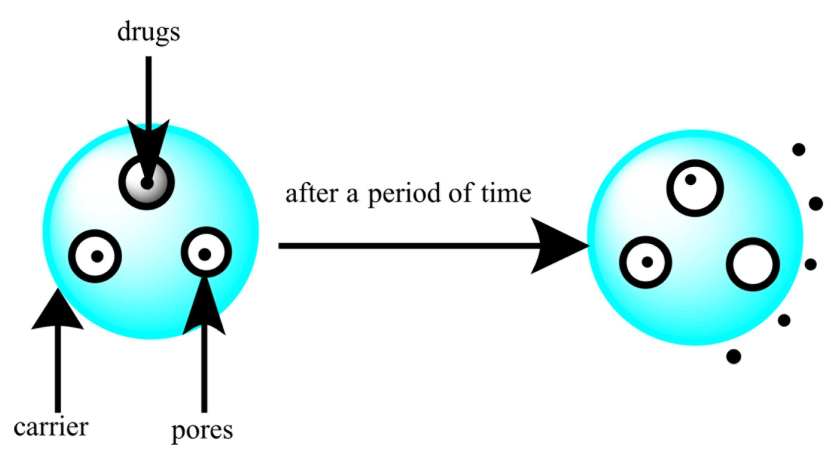

Figure 2: Principle of ceramic-based DDS

However, most anticancer drugs (e.g. doxorubicin as a typical chemotherapeutic drug was used in the present therapy of cancer) without targeting ability exhibit sideeffects to normal cells. Hence, exploring DDS for controlled, sustained and targeted release of anti-cancer drugs has attracted much attention from various fields to meet clinical requirements that maximum therapy effects along with minimal side effects.

\section{Common ceramic drug carriers}

\subsection{Hydroxyapatite( $\left.\mathrm{HAP}, \mathrm{Ca}_{10}\left(\mathrm{PO}_{4}\right)_{6}(\mathrm{OH})_{2}\right)$}

HAP is the main inorganic composition of hard tissues such as bone and teeth of vertebrates, etc. HAP occupies almost $60 \% \sim 70 \%$ of bone mineral content in human body. Thus it has been applied abundantly in the field of bone repair. It can be synthesized automatically in the alive or- ganic body, and it can resist the wet environment, avoid shrinkage and has adjustable hardness [16-20].

Nanostructured HAP has the following desirable properties: good biocompatibility, strong biological activity, biodegradability, osteoconductivity, nontoxicity, easy metabolism in vivo and hollow mesoporous structure. And hence it has been a desirable candidate for controlled and sustained release of proteins, genes and drugs in the field of DDS [21-23]. Plenty of studies have indicated their application in the field of targeted, controlled and sustained drug/protein/genes delivery system, which are summarized in Table 2.

Nowadays, researchers are facing plenty of challenges and limitations in this field, such as achieving targeted, controlled and sustained release of drugs, improving loading capacity of carriers, decreasing cytotoxicity of carriers and drugs, etc. Hence, numerous of researchers have carried out different studies to overcome the limitations.

Traditionally, drugs are taken 1-3 times a day via oral intake, however it is difficult to take drugs on schedule, especially for patients with depression, cancer and other chronic illness. In contrast, long-time DDS can release drug for several days or weeks. In recent years, many researchers are devoted themselves to achieving sustained drug release. Shyong et al. [24] synthesized HAP via coprecipitation method by mixing $\mathrm{Ca}(\mathrm{OH})_{2}$ and $\mathrm{H}_{3} \mathrm{PO}_{4}$, then loaded antidepressant orchlorapine (OLZ) into porous hydroxyapatite to construct HAP-OLZ. They demonstrated that HAP-OLZ achieved long-time release of OLZ in rats with induced depression, which could be more than 3 weeks after intramuscular injection. And they found this system enhanced locomotor activity, and ability of studying and remembering in rats with induced depression. Hence HAP could be used as carrier for sustained release of OLZ, and HAP-OLZ was favorable to solve the nonadhesive drug intake that occurs in the therapy of antidepressant via intramuscular injection.

Meanwhile, enhancing loading performance of carriers is one of the most attractive parts in the field of DDS. Ma et al. [25] synthesized HAP microspheres via hydrothermal method and the study suggested that they had ideal loading capacity of Ibuprofen (IBU) with $413.65 \mathrm{mg} / \mathrm{g}$, and the release of IBU was responsive to $\mathrm{pH}$. In a similar study, Yu et al. [26] prepared HAP using ibuprofen (IBU) as model drug. It indicated that HAP nanorod-assembled porous hollow polyhedral had a better drug loading capacity, which is desirable for the sustained drug release.

It was found that the properties of HAP also have significant influence on the drug encapsulation efficiency and the time of sustained release. Shi et al. [27] synthesized nano-HAP and micro-HAP by mixing $\mathrm{Ca}\left(\mathrm{NO}_{3}\right)_{2} \cdot 4 \mathrm{H}_{2} \mathrm{O}$ and 
Table 1: Experimental profiles of two kinds of HAP

\begin{tabular}{ccc}
\hline properties & nano-HAP & micro-HAP \\
\hline Shape & Rod-like & Miscropheres \\
Size of powders & Length of $150 \mathrm{~nm}$, width of $20 \mathrm{~nm}$ & Diameter of $15 \mu \mathrm{m}$ \\
Size of pores $(\mathrm{nm})$ & $3-4$ & $3-4,8-12$ \\
Surface areas $\left(\mathrm{m}^{2} / \mathrm{g}\right)$ & 84.48 & 17.31 \\
The amount of LF on the surface $\left(\mathrm{mg} / \mathrm{m}^{2}\right)$ & 2.93 & 1.08 \\
The maximum amount of adsorbed $\mathrm{LF}(\mu \mathrm{g} / \mathrm{mg})$ & 91.10 & 50.76 \\
\hline
\end{tabular}

$\left(\mathrm{CH}_{3} \mathrm{O}\right)_{3} \mathrm{P}$ via sol-gel method, and functionalized HAP with lactoferrin(LF) to form HAP-LF. The experimental profiles are summarized in Table 1. Comprehensively, nano-HAP had larger surface areas, amount of LF on the surface and maximum amount of adsorbed LF than micro-HAP. They indicated that HAP-LF enhanced the biocompatibility of HAP. It turned out that HAP can be applied as a controlled release carrier of LF that might be applied in the field of enhancement of bone regeneration, also could be a new biomaterial.

Currently, one of the most attractive composite carriers is related to the organic-inorganic composite which can combine the advantages of both the inorganic and organic materials. Organic materials have the advantages of high hydrophilicity, desirable biodegradablity and biocompatibility. Besides, inorganic biomaterials have high drug loading capacity and some are sensitive to magnetic field, heat, acidity, light and ultrasound. Hence, a lot of researchers modified inorganic particles with organics to overcome their respective shortages and enhance their performance in drug delivery. Meanwhile, organic-inorganic composite carriers not only had improved water solubility of drugs due to incorporation with high hydrophilic organic materials, but also possessed the characteristics of inorganic particles such as excellent drug loading capacity, controlled and sustained targeted delivery. For instance, carriers with high loading capacity and good targeted ability could be achieved through the hybrids of magnetic materials, ceramics and organic materials. Besides, it was found that the weight ratios of agents influence the properties of organic-inorganic composites. Therefore, organicinorganic composite carriers have emerged rapidly as a novel class of versatile porous biomaterial for drug delivery application [28-34]. They are summarized in Table 4, $5,6,9$.

Nowadays, many researchers have devoted themselves to optimize adsorption and release parameters of drugs/genes/proteins by controlling the crystallinity, structure and size of HAP. The concentration of modifiers (e.g., SDS (inositol hexakisphosphate and cyclohexane-

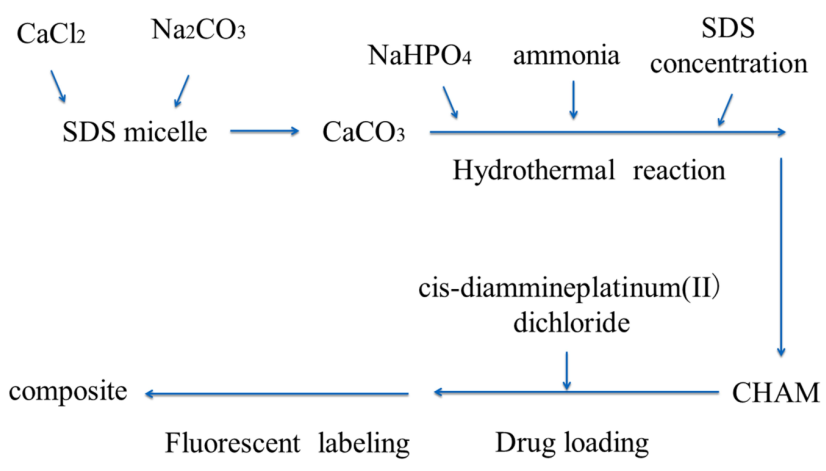

Figure 3: The process of CHAM synthesizing, drug loading and fluorescent labeling

1,2,3,4,5,6-hexacarboxylic acid)) have significant influence on the shape and size of HAP crystals. Qiao et al. [35] synthesized four kinds of hollow mesoporous carbonated $\mathrm{HAP}$ microsphere (CHAM) by mixing $\mathrm{CaCO}_{3}$ and sodium dodecyl sulfate (SDS) via hydrothermal method. The process of CHAM synthesizing, drug loading and fluorescent labeling are shown in Figure 3, and some experimental results of 4 HAP groups are shown in Table 3. The concentration of SDS can be applied to controlling the structure, wall thickness and size of CHAM. It was found that the concentration of SDS contributed to increase drug entrapment efficiency, sustained release, biocompatibility and osteoconductivity. The $\mathrm{pH}$-dependent drug release could be attributed to the degradation of CHAMs that was sensitive to $\mathrm{pH}$. The shape of HAP crystals played an important role in the adsorption of proteins and drugs, and it can increase the drug entrapment efficiency and sustained drug release capacity by decreasing the crystallinity of HAP. As a whole, C group of CHAM might be the most desirable candidate for controlling and sustained release of cisdiaminedichloroplatinum (CDDP). The study suggested this system to be an ideal option for anti-cancer therapy because of their highest lethality on human squamous cell in vitro and entrapment of cis-diammineplatinum(II) dichloride (CDDP). In addition, this system might be applied in the therapy of cancer because of its satisfactory 


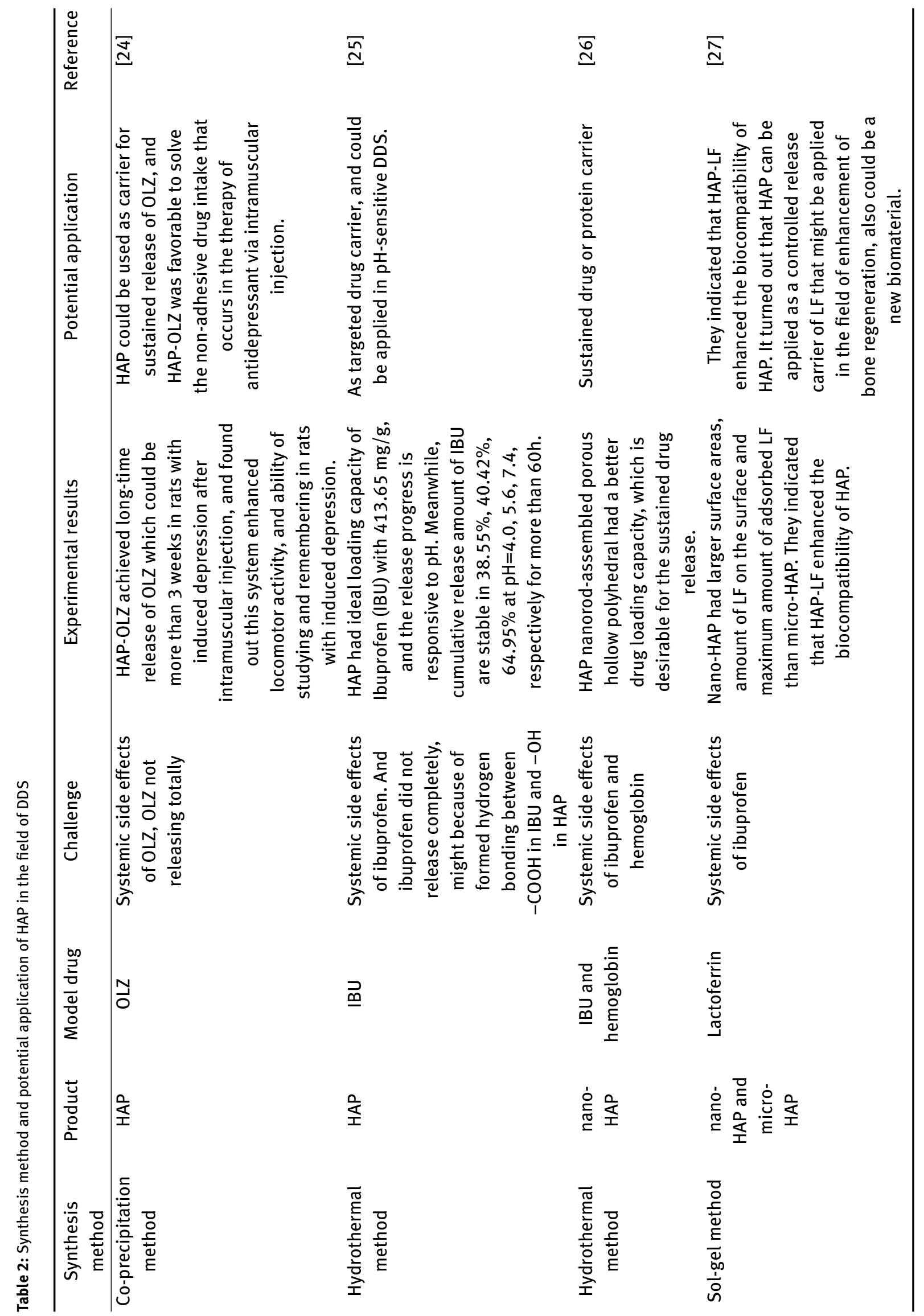


Table 3: Some experimental results of 4 HAP groups

\begin{tabular}{|c|c|c|c|c|}
\hline HAP group & A & B & $\mathrm{C}$ & D \\
\hline SDS concentration $(\mathrm{mg} / \mathrm{ml})$ & 1 & 2.33 & 4.66 & 10 \\
\hline Shape of crystals & Needle-like & Needle-like & Rod-like & Rod-like \\
\hline Diameter of particles & $\begin{array}{c}90 \% \text { under } \\
3 \mu \mathrm{m}\end{array}$ & About $3 \mu \mathrm{m}$ & $3-5 \mu \mathrm{m}$ & $\begin{array}{c}\text { Two sub-groups: } 0.6 \mu \mathrm{m} \\
\text { and } 5 \mu \mathrm{m}\end{array}$ \\
\hline Surfaces areas of particles $\left(\mathrm{m}^{2} / \mathrm{g}\right)$ & 17.58 & - & - & 25.12 \\
\hline Biodegradability & - & - & - & Fastest \\
\hline Drug entrapment efficiency (\%) at $24 \mathrm{~h}$ & $\approx 30$ & $\approx 50$ & $\approx 65$ & $\approx 50$ \\
\hline Cumulative drug release $(\mu \mathrm{g})$ at $\mathrm{pH} 5$ & $\approx 70$ & $\approx 95$ & $\approx 120$ & $\approx 100$ \\
\hline Cumulative drug release $(\mu \mathrm{g})$ at $\mathrm{pH} 7$ & $\approx 60$ & $\approx 70$ & $\approx 85$ & $\approx 75$ \\
\hline Tumor cell survival rate (\%) at $24 \mathrm{~h}$ & $\approx 79$ & $\approx 78$ & $\approx 65$ & $\approx 77$ \\
\hline Tumor cell survival rate (\%) at $72 \mathrm{~h}$ & $\approx 40$ & $\approx 43$ & $\approx 20$ & $\approx 35$ \\
\hline
\end{tabular}

characteristics of sustained release of drugs, biodegradability and sensitivity to $\mathrm{pH}$. In a similar study, Morsy R et al. [36] synthesized HAP/wollastonite (HAP/WT) composite by Two-Step co-precipitation method and the size of the as-prepared particles was less than $1 \mu \mathrm{m}$. The study suggested that HAP/WT composites might be potential drug carriers and can be applied as bone repair materials.

Shuai et al. [37] fabricated sericin-HAP composite microspheres for loading DOX. They showed that controlled release of DOX was sensitive to $\mathrm{pH}$, and sustained release of DOX could be realized. Furthermore, rate of DOX release was higher in acidic environment than in physiological environment which typical cancer and normal cells respectively possessed. This unique characteristic could decrease the toxicity to the normal tissue. This system had a potential application in DDS.

Simionescu et al. [38] prepared nano-HAP modified by biopolymers/poly(epsilon-caprolactone)/polyethylenimine by cryoablation. The as-prepared composites had controllable porosity, excellent biodegradation and lower cytotoxicity than pure PEI25-pDNA. It was found that the content of nano-HAP had sufficient influence on the cohesivity and uniformity of the composites. Besides, the composites released PEI25-pDNA over 22 days with high expression.

Zeng et al. [39] prepared $\mathrm{Ba}^{2+}$-doped $\mathrm{HAP} / \mathrm{Cu}$-doped quantum dots (QDs)/hyaluronic acid (HA) composites. In those composites $\mathrm{Ba}^{2+}$ used as CT contrast agent, $\mathrm{Cu}$ doped quantum dots (QDs) as NIR fluorescent agent, and $\mathrm{HA}$ as fluorescent and cancerous cell targeting agent to target tumor and near infrared (NIR) imaging. The study indicated that the as-prepared composites not only could keep desirable dispersion of HAP but also had capacity of targeting tumor and NIR laser radiation at $700 \mathrm{~nm}$, along with desirable photostability and excellent biocompatibility. Hence, it could be applied to CT and fluorescence bi- modal imaging and early diagnosis and targeted therapy of tumor.

\subsection{Tricalcium phosphate(TCP, $\left.\mathrm{Ca}_{3}\left(\mathrm{PO}_{4}\right)_{2}\right)$}

TCP can be divided into two types: $\alpha$-TCP as high temperature phase and $\beta$-TCP as lower temperature phase. $\beta$-TCP has better biodegradability, biocompatibility and thermodynamic stability than $\alpha$-TCP [40-43]. In this context, $\beta$ TCP has been applied as one of the most attractive carriers in the field of DDS with abilities of controlled, sustained and targeted release of drugs. And implementing regulator (sodium dodecyl benzene sulfonate) can regulate the size, distribution and shape of $\beta$-TCP. Lots of studies have indicated their application in the field of targeted, controlled and sustained drugs/proteins/genes delivery system, which are summarized in Table 5.

Hoover et al. [44] fabricated silver doped $\beta$-TCP with three concentrations of $\mathrm{Ag}_{2} \mathrm{O}, 0.5 \mathrm{wt} \% \mathrm{Ag}_{2} \mathrm{O}, 1 \mathrm{wt} \% \mathrm{Ag}_{2} \mathrm{O}$ and $2 \mathrm{wt} \% \mathrm{Ag}_{2} \mathrm{O}$. According to the immersion test, cumulative amount of $\mathrm{Ag}^{+}$release was $80-90 \mu \mathrm{mol}$ in 60 days. Besides, it was favorable for the cell growth without obvious cytotoxicity even for $2 \mathrm{wt} \%$ of $\mathrm{Ag}_{2} \mathrm{O}$. The study indicated this system could achieve sustained release of silver.

Mirjalili et al. [45] fabricated $\beta$-TCP/carbon nanotube (CNT) composite and found no significant agglomeration with $1 \mathrm{wt} \%$ of CNT, and distribution of CNT, structure and size could be controlled by $2 \mathrm{wt} \%$ of sodium dodecyl benzene sulfonate (SDBS).Therefore, it might be feasible to apply $\beta$-TCP as both DDS and bone regeneration materials in the same time and make full use of the properties of $\beta$-TCP.

Lin et al. [46] synthesized PLGA/ $\beta$-TCP scaffolds with PLGA nanoparticles as DDS for loading OIC-A006. The drug release assay indicated that the pattern of OIC-A006 


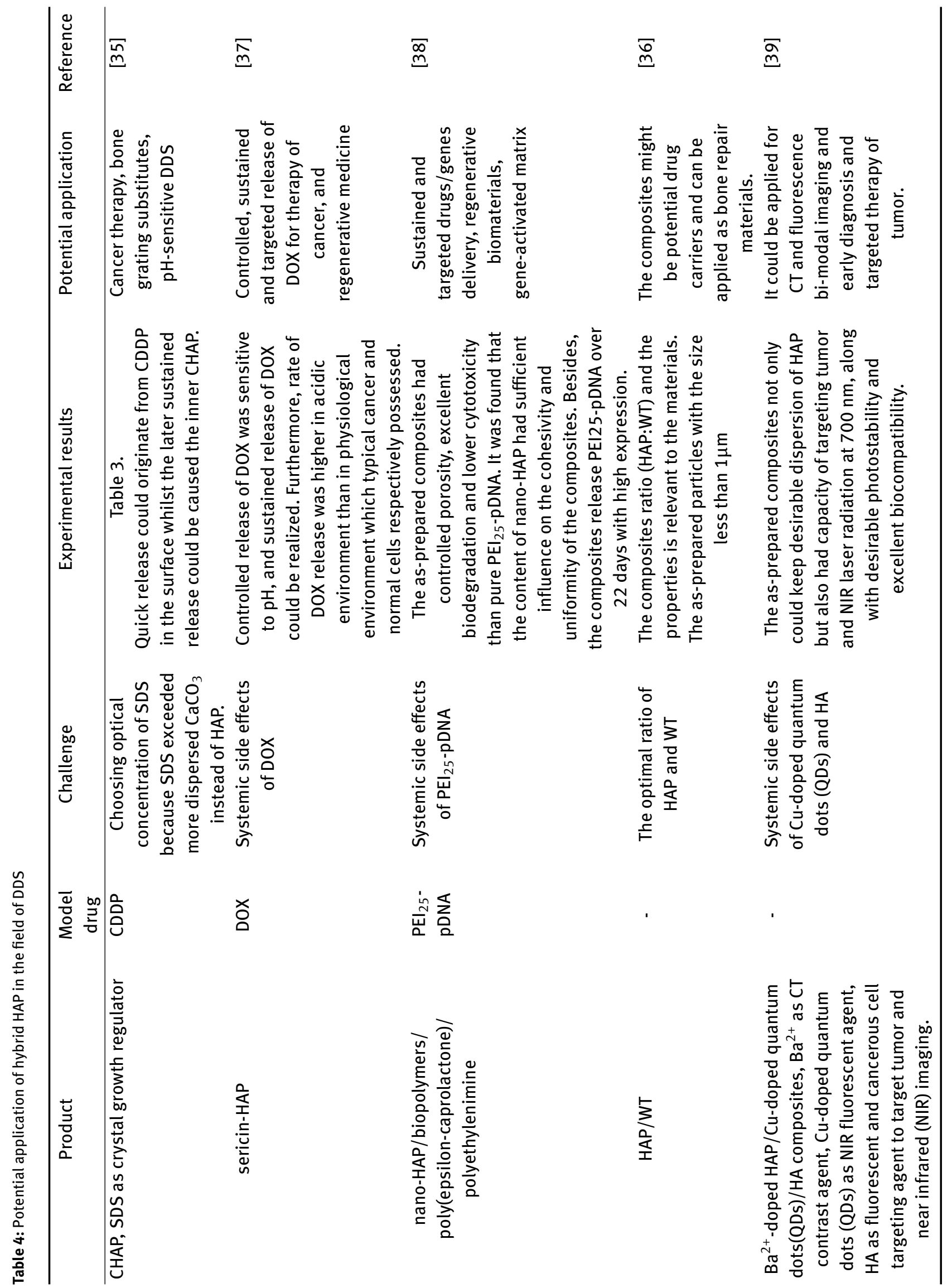


Table 5: Potential application of $\beta$-TCP in the field of DDS

\begin{tabular}{|c|c|c|c|c|c|c|}
\hline Synthesis method & Product & Model drug & Challenge & Experimental results & Potential application & $\overline{\text { Reference }}$ \\
\hline $\begin{array}{l}\text { Liquid porogen } \\
\text { based method }\end{array}$ & $\begin{array}{c}\text { Silver } \\
\text { doped } \\
\beta \text {-TCP }\end{array}$ & $\mathrm{Ag}_{2} \mathrm{O}$ & $\begin{array}{l}\text { Systemic } \\
\text { side effects } \\
\text { of } \mathrm{Ag}_{2} \mathrm{O}\end{array}$ & $\begin{array}{l}\text { Cumulative amount of } \mathrm{Ag}^{+} \text {release } \\
\text { was } 80-90 \mu \mathrm{mol} \text { in } 60 \text { days, } \\
\text { increasing osteoblast cell } \\
\text { proliferation along with } \\
\text { osteoconductio without obvious } \\
\text { cytotoxic even for the } 2 \mathrm{wt} \% \text { of } \\
\mathrm{Ag}_{2} \mathrm{O} \text {. }\end{array}$ & $\begin{array}{l}\text { Sustained release of } \\
\text { antibiotics against } \\
\text { infection in bone } \\
\text { graft surgery. }\end{array}$ & [44] \\
\hline $\begin{array}{l}\text { Solution } \\
\text { precipitation } \\
\text { method }\end{array}$ & $\beta$-TCP/CNT & - & $\begin{array}{l}\text { Optical con- } \\
\text { centration } \\
\text { of SDBS }\end{array}$ & $\begin{array}{c}\text { No significant agglomeration with } \\
1 \text { wt } \% \text { of CNT, appearance of } \\
\text { apatite layer on the surface of } \\
\text { nanocomposites. }\end{array}$ & $\begin{array}{c}\text { Bone graft } \\
\text { biomaterials }\end{array}$ & [45] \\
\hline $\begin{array}{l}\text { Ice bath extraction } \\
\text { and freeze-drying }\end{array}$ & $\begin{array}{l}\text { PLGA } / \beta \text { - } \\
\text { TCP } \\
\text { scaffolds } \\
\text { with PLGA }\end{array}$ & OIC-A006 & $\begin{array}{l}\text { Systemic } \\
\text { side effects } \\
\text { of } \\
\text { OIC-A006 }\end{array}$ & $\begin{array}{l}\text { The pattern of OIC-A006 release } \\
\text { was biphasic, and sustained } \\
\text { release of OIC-A006 had an } \\
\text { effective impact on cell } \\
\text { proliferation and adhesion. The } \\
\text { system that OIC-A006 was loaded } \\
\text { by PLGA/ } \beta \text {-TCP scaffolds with PLGA } \\
\text { nanoparticles was favorable to } \\
\text { osteoinduction and bone } \\
\text { formation. }\end{array}$ & $\begin{array}{l}\text { Osteoinduction and } \\
\text { bone formation }\end{array}$ & [46] \\
\hline
\end{tabular}

release was biphasic, and sustained release of OIC-A006 had an effective impact on cell proliferation and adhesion. The system that OIC-A006 was loaded by PLGA/ $\beta$-TCP scaffolds with PLGA nanoparticles was favorable to osteoinduction and bone formation.

\subsection{Silicon-based ceramics}

Mesoporous $\mathrm{SiO}_{2}$ nanopaticles (MSNs) have the following desirable characteristics: low cost, large specific surface area and specific pore volume, uniform and adjustable size of pores, mesoporous structure, high loading capacity of drugs, non-toxicity, desirable biocompatibility, biodegradation and stability. Accordingly, they have huge potential in the field of DDS for controlled and sustained release of drugs and targeted delivery. Usually, the synthesis method is the hydrolysis of tetraethyl lorthosilicate (TEOS, $\left.\mathrm{Si}\left(\mathrm{OC}_{2} \mathrm{H}_{5}\right)_{4}\right)$ [47-52]. A number of studies indicating their applications in the field of targeted, controlled and sustained drugs/proteins/genes delivery system are summarized in Table 6.

Bardhan et al. [53] prepared MSNs with size of 150$200 \mathrm{~nm}$ by hydrolysis of tetraethyl lorthosilicate (TEOS, $\left.\mathrm{Si}\left(\mathrm{OC}_{2} \mathrm{H}_{5}\right)_{4}\right)$. They used fluorescence anisotropy to monitor the trail of DOX loaded by MSNs. The most advantageous part was that the platform released drug at $\mathrm{pH}$ of cellular physiological microenvironment. The study demonstrated that MSNs/DOX system had stronger capacity of up- take and stable release of DOX than free DOX in the therapy of primary non-keratinized squamous of oral mucosal. This unique characteristic could be applied for therapy of diseases, such as cerebral ischemia reperfusion injury and cancer.

Yang et al. [54] synthesized MSNs-Au loaded DOX where gold acted as gatekeepers of MSNs, these composites were applied as redox-sensitive DDS for chemophotothermal synergistic therapy. It was shown that DOX released faster via stimulation of glutathione (GSH) or near infrared laser than free DOX.

Zhang et al. [55] prepared ZnO/MSNs composites. They found that the composites would release drug in the acidic microenvironment of tumor cells in comparison to zero release in the physiological microenvironment of the normal tissues. Besides, the cytotoxicity of ZnO QDs might endow composites with synergistic curative effect for tumor. Hence this system could improve the index of cancerous therapy and had significant potential for the therapy of cancer.

Wang et al. [56] prepared indocyanine green (ICG) loaded $\mathrm{W}_{18} \mathrm{O}_{49} / \mathrm{MSN}$. It showed that the system produced synergistic photothermal therapy and lethal effect to B16 tumor cells through the motivation of $808 \mathrm{~nm}$ NIR laser, and the shape of $\mathrm{W}_{18} \mathrm{O}_{49}$ can be controlled without surface modification. This system had potential application in the field of NIR-sensitive platform for therapy of cancer and the real-time track of photothermal therapy. 


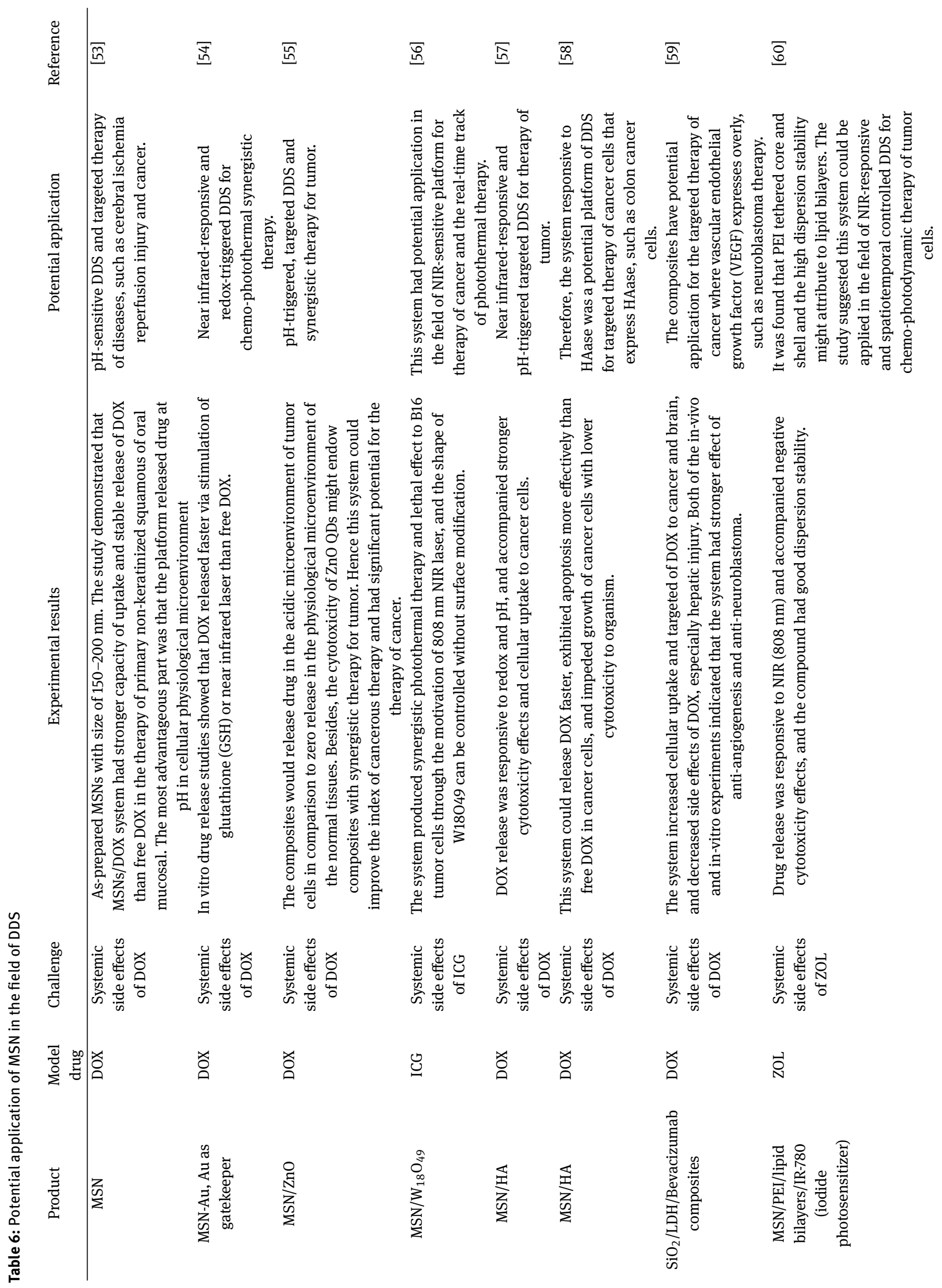




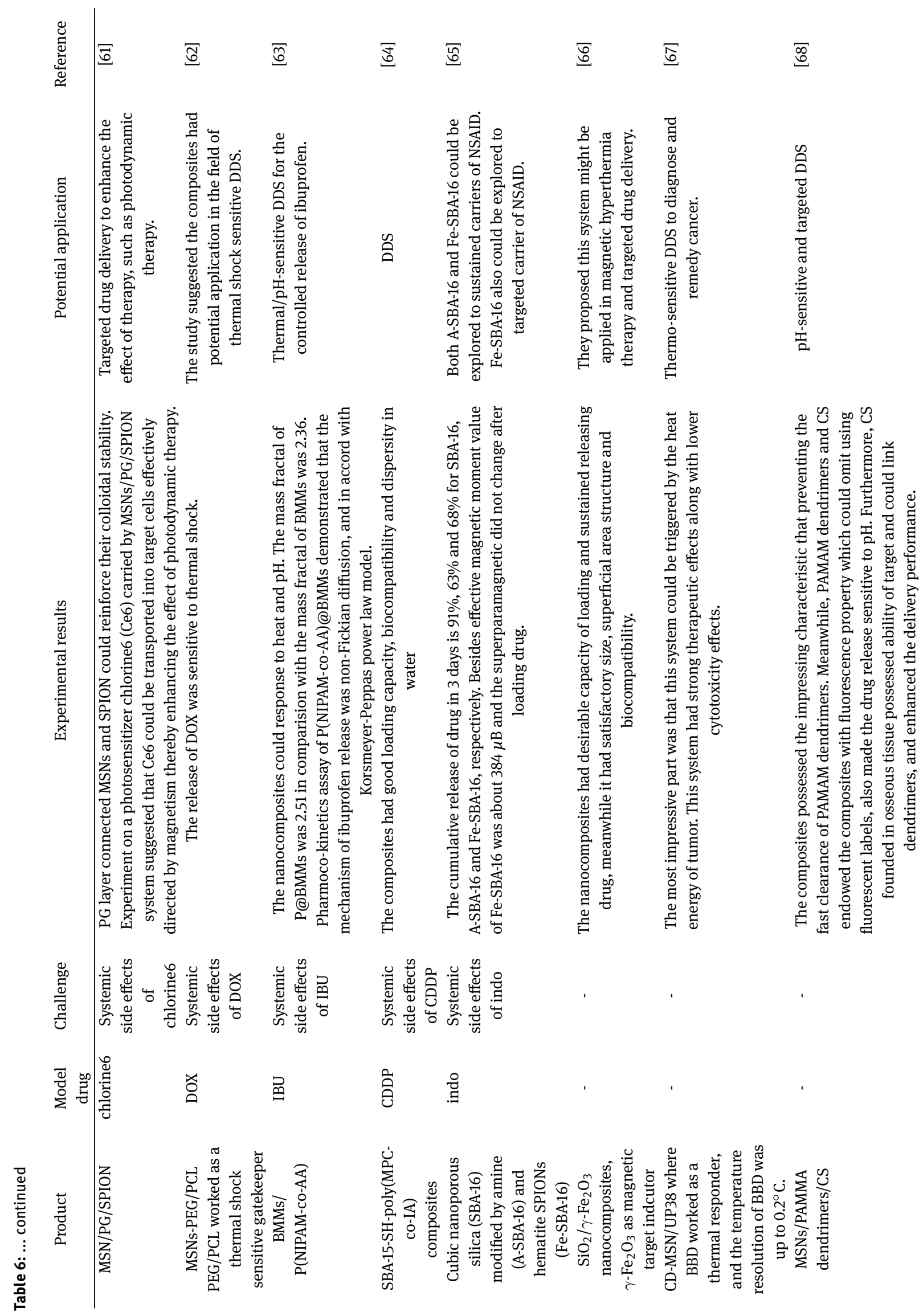




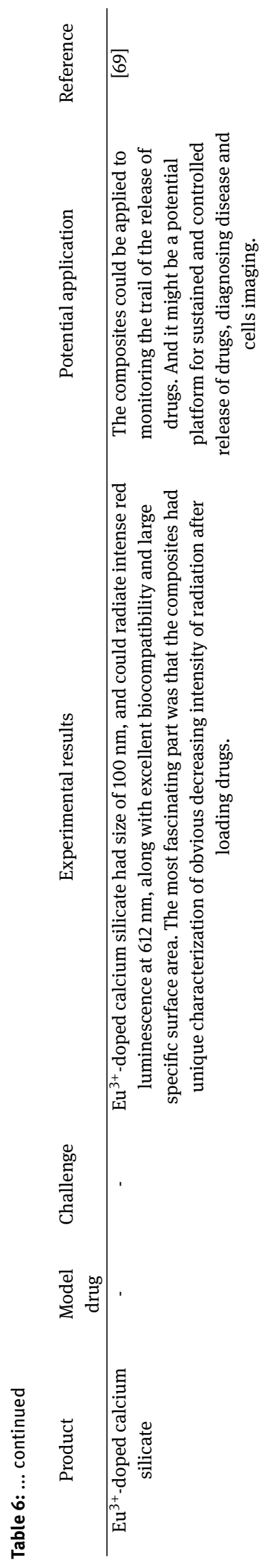


Lin et al. [57] synthesized MSNs-hyaluronic acid (HA) loaded DOX where MSNs functionalized by HA as a redox and $\mathrm{pH}$ dual stimulate-sensitive DDS. The results indicated that DOX release was responsive to redox and $\mathrm{pH}$, and accompanied stronger cytotoxicity effects and cellular uptake to cancer cells, which enable the composites to be applied in the field of tumor therapy.

Zhang et al. [58] synthesized MSNs/hyaluronic acid (HA) as hyaluronidase (HAase) sensitive DDS. This system could release DOX faster, exhibited more effective apoptosis than free DOX in cancer cells, and impeded growth of cancer cells with lower cytotoxicity to organism. Therefore, the system responsive to HAase was a potential platform of DDS for targeted therapy of cancer cells that express HAase, such as colon cancer cells.

$\mathrm{Zhu}$ et al. [59] fabricated $\mathrm{SiO}_{2} /$ lactate dehydrogenase (LDH)-Bevacizumab composites as DDS to load DOX. Besides, vascular endothelial growth factor (VEGF) was applied as a target because of its abnormal expression in tumor. The study demonstrated that this system increased cellular uptake and targeted of DOX to cancer and brain, and decreased side effects of DOX, especially hepatic injury. Both of the in-vivo and in-vitro experiments indicated that the system had stronger effect of antiangiogenesis and anti-neuroblastoma. Hence the composites have potential application for the targeted therapy of cancer where vascular endothelial growth factor (VEGF) expresses overly, such as neuroblastoma therapy.

Liu et al. [60] synthesized MSNs-zoledronic acid (ZOL)/tethered with lipid bilayers (tLB)-IR-780 iodide system as a NIR-responsive DDS. The study indicated that drug release was responsive to NIR and accompanied negative cytotoxicity effects, and the compound had good dispersion stability. The study suggested this system could be applied in the field of NIR-responsive DDS for tumor cells.

Yang et al. [61] prepared the MSNs/PG/SPION system where MSNs were coated by super paramagnetic iron oxide nanoparticles (SPION). The study revealed polyglycerol (PG) layer connected MSNs and SPION could reinforce their colloidal stability. Experiment on a photosensitizer chlorine6 (Ce6) carried by MSNs/PG/SPION system suggested that $\mathrm{Ce} 6$ could be transported into target cells effectively directed by magnetism thereby enhancing the effect of photodynamic therapy.

Cho et al. [62] structured MSNs-PEG/PCL where polyethylene glycol (PEG)/polycaprolactone (PCL) worked as a thermal shock sensitive gatekeeper. The assay indicated that the release of DOX was sensitive to thermal shock. The study suggested the composites had potential application in the field of thermal shock sensitive DDS.
Jin et al. [63] fabricated bimodal mesoporous silica nanoparticles (BMMs)/poly(N-isopropylacrylacrylamide)-co-poly(acrylic acid) (P(NIPAM-co-AA)) to load ibuprofen. This system was responsive to temperature and $\mathrm{pH}$. Pharmoco-kinetics assay of P(NIPAM-coAA)@BMMs demonstrated a non-Fickian diffusion mechanism of ibuprofen release, and in accord with KorsmeyerPeppas power law model.

Huang et al. [64] fabricated SBA-15-SH-poly(MPC-coIA) composites to load CDDP, and synthetic route was shown in Figure 4. It was found that the composites had good loading capacity, biocompatibility and dispersity in water.

$$
\begin{aligned}
& \text { poly(ethylene glycol)-block- } \\
& \text { poly(propylene glycol)-block- } \\
& \text { poly (ethylene glycol) } \\
& \text { tetraethoxysilane } \underset{\text { hydrolysis }}{\stackrel{\downarrow}{\longrightarrow}} \text { SBA-15 } \underset{\text { co-condensation }}{\stackrel{\downarrow}{\longrightarrow} \text { SBA-15-SH }} \\
& \text { 2-methacryloyloxy ethyl } \\
& \text { phosphorylcholine (MPC) and } \\
& \text { itaconic acid (IA) } \\
& \text { SBA-15-SH-poly(MPC-co-IA) } \\
& \text { chain transfer free radical } \\
& \text { cisplatin } \longrightarrow \text { Drug loading polymerization } \\
& \text { composite }
\end{aligned}
$$

Figure 4: The synthetic route of CHAM and drug loading

Zelenak et al. [65] investigated the properties of cubic nanoporous silica (SBA-16) modified by amine (A-SBA-16) and hematite SPIONs (Fe-SBA-16) loaded with indomethacin (indo), a typical nonsteroidal antiinflammatory drug (NSAID). The cumulative release of drug in 3 days was $91 \%, 63 \%$ and $68 \%$ for SBA- 16 , A-SBA16 and Fe-SBA-16, respectively. Besides, effective magnetic moment value of Fe-SBA-16 was about $384 \mu_{B}$ and the superparamagnetic property did not change after loading drug. Hence both A-SBA-16 and Fe-SBA-16 could be explored to be sustained carriers of NSAID. Fe-SBA-16 could also be explored to be targeted carrier of NSAID.

Wan et al. [66] prepared walnut kernel-like $\mathrm{SiO}_{2} / \gamma$ $\mathrm{Fe}_{2} \mathrm{O}_{3}$ composite by doping $\gamma-\mathrm{Fe}_{2} \mathrm{O}_{3}$ into mesoporous $\mathrm{SiO}_{2}$. It was found that the nanocomposite had desirable capacity of loading and sustained releasing drug, meanwhile it had satisfactory size, superficial area structure and biocompatibility. They proposed that this system might be applied in magnetic hyperthermia therapy and drug targeted delivery. 
Dong et al. [67] fabricated CD-MSN/UP38 where 4Benzylamino-7-nitro-2,1,3-benzoxadiazole (BBD) was used as a thermal responder by chemical synthesis and nanotechnology, and the temperature resolution of BBD was up to $0.2^{\circ} \mathrm{C}$. The most impressive part was that this system could be triggered by the heat energy of tumor. This system had strong therapeutic effects along with lower cytotoxicity effects, which enable it to be applied in the field of thermal-sensitive DDS to diagnose and remedy cancer.

$\mathrm{Xu}$ et al. [68] assembled MSNs/polyamidoamine (PAMMA) dendrimers/chondroitin sulfate (CS) by layer-bylayer assembly method. The composites possessed the impressive characteristic that preventing the fast clearance of polyamidoamine (PAMAM) dendrimers. Meanwhile, PAMAM dendrimers and CS endowed the composites with fluorescence property which helped to avoid the need of external doping of fluorescent substances, and made the drug release sensitive to $\mathrm{pH}$. Furthermore, CS found in osseous tissue possessed ability of targeting, linking dendrimers, and enhancing the delivery performance.

In addition, some silicon-contained materials are also considered as good candidate for carriers. For instance, in the study of Zhang et al. [69], it was found that the size of $\mathrm{Eu}^{3+}$-doped calcium silicate was $100 \mathrm{~nm}$, and could radiate intense red luminescence at $612 \mathrm{~nm}$, along with excellent biocompatibility and large specific surface area. The most fascinating part was that the composites had unique characterization of obvious decreasing intensity of radiation after loading drugs, which could be applied to monitor the trail of the release of drugs. And the composites might be potential platform for sustained and controlled release of drug, diagnoses of disease and cells imaging.

\subsection{Zeolitic Imidazole Framework (ZIFs)}

The applications of conventional materials for DDS were restricted by their cytotoxicity and uncontrolled drug release, etc. Herein, ZIFs have emerged rapidly as a novel class of versatile porous biomaterial for application in the field of DDS owing to their unique priority of structural diversity, high specific surface area, desirable chemical and thermodynamic stability, non-toxicity and desirable biocompatibility [70-72].

Adhikari et al. [73] investigated the performance of 2 types of carriers, i.e., ZIF-7 and ZIF-8, for the release of DOX. It was shown that DOX was encapsulated easily by both carriers, and delivery duration of DOX was $10 \mathrm{~h}$ and $3 \mathrm{~h}$ for ZIF-7 and ZIF-8, respectively. Besides, controlled drug delivery time was $10 \mathrm{~h}$ owing to rigidity of ZIF-7. Furthermore, ZIF-8 was sensitive to $\mathrm{pH}$ and could release DOX in acidic environment which tumor cells possess typically, that was not found in ZIF-7. Experimental results were shown in Table 7 . Therefore, the drug release could be controlled by using various characteristics of different ZIFs. This provided reference for future exploration of DDS for therapy of diseases, such as cancer.

Table 7: Experimental results of 2 groups

\begin{tabular}{ccc}
\hline Experimental results & $\begin{array}{c}\text { DOX loaded } \\
\text { ZIF-7 }\end{array}$ & $\begin{array}{c}\text { DOX loaded } \\
\text { ZIF-8 }\end{array}$ \\
\hline pH-sensitive & $\sqrt{ }$ & $\times$ \\
Controlled drug & 10 & 3 \\
delivery time (h) & & \\
\hline
\end{tabular}

\subsection{Ceramics based on iron oxide nanoparticles}

Nowadays, iron oxide nanoparticles $\left(\mathrm{Fe}_{3} \mathrm{O}_{4}\right.$ and $\left.\mathrm{Fe}_{2} \mathrm{O}_{3}\right)$ had been used in the field of DDS as magnetic metal organic frameworks (MOFs) and inductor for targeted delivery in terms of its unique magnetic property. A lot of studies indicated their application in targeted, controlled and sustained DDS are summarized in Table 8-9.

Table 8: Synthesis method of iron oxide nanoparticles in the field of DDS

\begin{tabular}{|c|c|c|}
\hline Synthesis method & Product & Reference \\
\hline $\begin{array}{c}\text { Microwave } \\
\text { irradiation technique }\end{array}$ & $\begin{array}{c}\mathrm{Fe}_{3} \mathrm{O}_{4}-\mathrm{NH}_{2} / \mathrm{MIL} 101-\mathrm{NH}_{2} \\
\text { nanocomposites }\end{array}$ & [74] \\
\hline Copolymerizing & $\mathrm{Fe}_{3} \mathrm{O}_{4} / \mathrm{P}(\mathrm{NIPAM}-\mathrm{CO}-\mathrm{MAA})$ & [75] \\
\hline $\begin{array}{c}\text { W/O/W emulsion } \\
\text { technique }\end{array}$ & $\mathrm{Fe}_{3} \mathrm{O}_{4} / \mathrm{PLGA}$ or HAP/PLGA. & [76] \\
\hline $\begin{array}{l}\text { Ultrasound assisted } \\
\text { precipitation method }\end{array}$ & $\begin{array}{c}\mathrm{Fe}_{3} \mathrm{O}_{4} / \mathrm{SiO}_{2} / \mathrm{HAP} \\
\text { nanocomposites } \\
\text { functionalized by APTES }\end{array}$ & [78] \\
\hline $\begin{array}{l}\text { Co-precipitation } \\
\text { approach }\end{array}$ & $\begin{array}{c}\text { Iron oxide nanoparticles } \\
\left(\mathrm{IONP}\left(\mathrm{Fe}_{3} \mathrm{O}_{4} / \mathrm{Fe}_{2} \mathrm{O}_{3}\right)\right) \\
\text { dual-coated by HAP and } \\
\mathrm{NaAlg}\end{array}$ & [79] \\
\hline
\end{tabular}

Li et al. [74] fabricated DOX-loaded $\mathrm{Fe}_{3} \mathrm{O}_{4}-\mathrm{NH}_{2} /$ MIL101$\mathrm{NH}_{2}$ composites as DDS. The system had great surface areas $\left(96.04 \mathrm{~m}^{2} / \mathrm{g}\right)$ and volume $\left(22.07 \mathrm{~cm}^{3} / \mathrm{g}\right)$, and the loading capacity of $36.02 \%$. Furthermore, DOX release was sensitive to $\mathrm{pH}$. In addition, the system had desirable biocompatibility and low cytotoxicity, which is better than the 


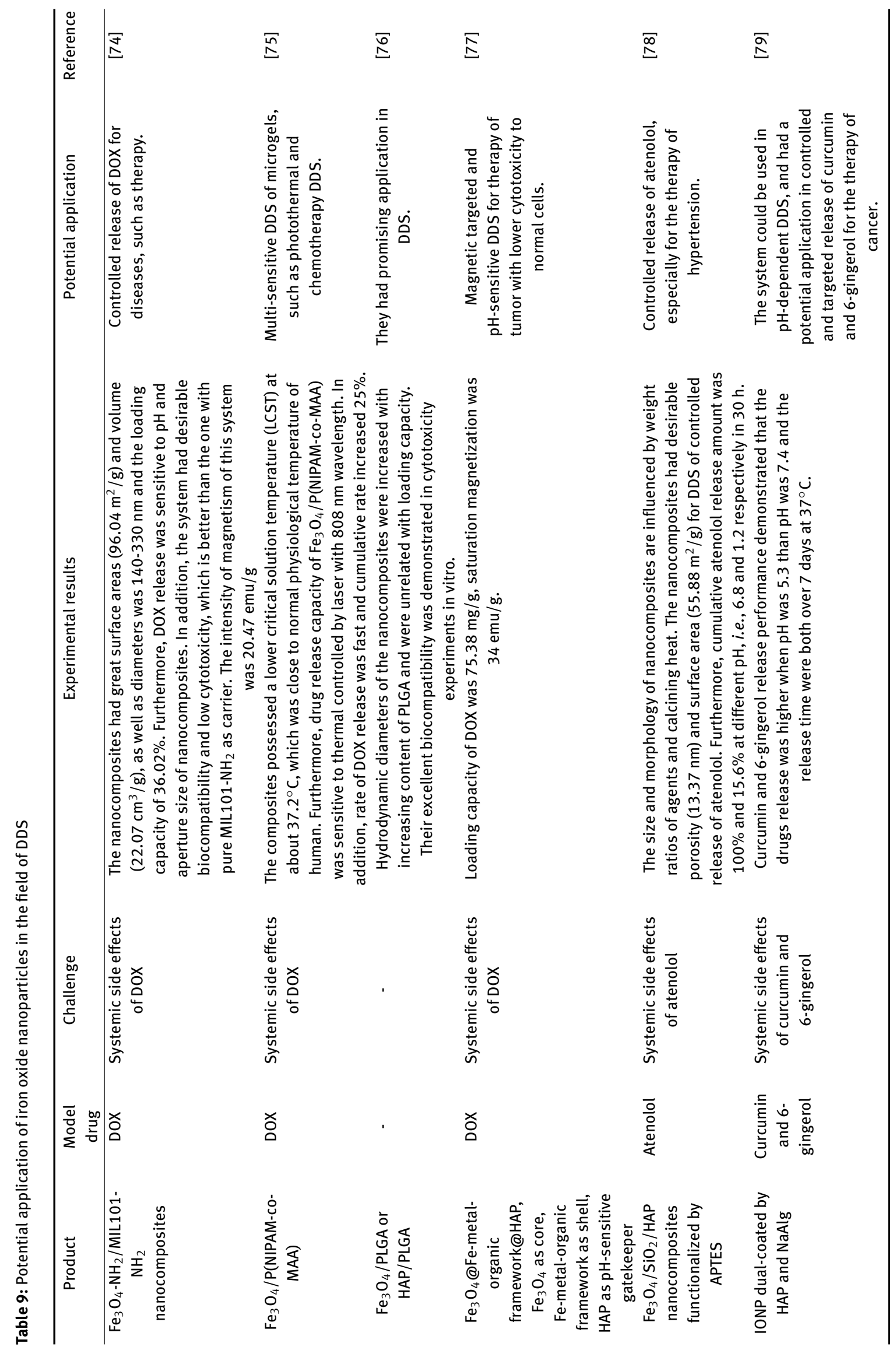


one with pure MIL101- $\mathrm{NH}_{2}$ as carrier. The intensity of magnetism of nanocomposites was $20.47 \mathrm{emu} / \mathrm{g}$, which hinted that the system was sensitive to magnetism.

Qi et al. [75] fabricated $\mathrm{Fe}_{3} \mathrm{O}_{4} /$ poly(N-isopropylacrylacrylamide)-co-poly(methacrylic acid) (P(NIPAMco-MAA)) by copolymerizing poly(N-isopropylacrylacrylamide) with methacrylic acid in water phase that containing $\mathrm{Fe}_{3} \mathrm{O}_{4}$ modified by oleic acid. Assay indicated that the composites possessed a lower critical solution temperature (LCST) at about $37.2^{\circ} \mathrm{C}$, which was close to normal physiological temperature of human. Furthermore, drug release capacity of $\mathrm{Fe}_{3} \mathrm{O}_{4} / \mathrm{P}$ (NIPAM-co-MAA) was sensitive to thermal controlled by laser with $808 \mathrm{~nm}$ wavelength. In addition, rate of DOX release was fast and cumulative rate increased by $25 \%$. Hence, the composites had potential application in multi-sensitive DDS of microgels, such as photothermal and chemotherapy DDS.

Bootdee et al. [76] fabricated composite composed of $\mathrm{Fe}_{3} \mathrm{O}_{4} /$ poly(D,L-lactide-co-glycolide)(PLGA) or HAP/PLGA. The weight ratios of $\mathrm{Fe}_{3} \mathrm{O}_{4}$ or HAP in the PLGA varied from about 5 to 60 wt $\%$ with various weight percent of $\mathrm{Fe}_{3} \mathrm{O}_{4}$ or HAP and PLGA in the oil phase. Hydrodynamic diameters of the nanocomposites were increased with increasing content of PLGA and were unrelated with loading capacity. Their excellent biocompatibility was demonstrated in cytotoxicity experiments in vitro. They had promising application in DDS.

Yang et al. [77] fabricated pH-responsive drug delivery system: $\mathrm{Fe}_{3} \mathrm{O}_{4} / \mathrm{Fe}-\mathrm{MOF} / \mathrm{HAP}$ which had a magnetic core coated Fe-MOF (metal-organic framework). In this system, HAP was pH-responsive gatekeeper to control the release of drug. The study indicated their loading capacity of doxorubicin (DOX) was $75.38 \mathrm{mg} / \mathrm{g}$ and their intensity of magnetic field was $34 \mathrm{emu} / \mathrm{g}$, which endowed this system with targeted ability on tumor tissue while decreasing toxicity to normal cells.

Sobhan et al. [78] synthesized $\mathrm{Fe}_{3} \mathrm{O}_{4} / \mathrm{SiO}_{2} / \mathrm{HAP}$ nanoparticles functionalized by 3-aminopropyl triethoxysilane (APTES). The system had desirable porosity $(13.37 \mathrm{~nm})$ and surface area $\left(55.88 \mathrm{~m}^{2} / \mathrm{g}\right)$ for DDS of controlled release of atenolol. Furthermore, cumulative atenolol release amount was $100 \%$ and $15.6 \%$ at different $\mathrm{pH}$, i.e., 6.8 and 1.2 respectively in $30 \mathrm{~h}$.

Manatunga et al. [79] fabricated iron oxide nanoparticles (IONP) dual-coated by HAP and sodium alginate (NaAlg) to be pH-dependent DDS. Curcumin and 6gingerol release performance demonstrated that the drugs release was higher when $\mathrm{pH}$ was 5.3 than $\mathrm{pH}$ was 7.4 and the release time both lasted for over 7 days at $37^{\circ} \mathrm{C}$. The system could be used in pH-dependent DDS, and had a potential application in controlled and targeted release of curcumin and 6-gingerol for the therapy of cancer.

\subsection{Alginate-brushite}

Besides, Dabiri et al. [80] fabricated composites composed of alginate-brushite (Alg-Bru) and hydrogel by a novel insitu synthesizing strategy to load IBU. It was found that the composites were sensitive to acidity, meanwhile the mechanical properties of composites were improved by the brushite, swelling ratio of alginate was limited by brushite. However, brushite did not increase entrapment efficiency (\%EE). The most impressive part was that brushite led the composites to release drug in a controlled gradual manner to avoid burst drug release of alginate.

\section{Conclusions}

Ceramics materials have numerous of merits such as simple method of preparation, adjustable size and structure, low toxicity, desirable stability under physiological conditions and biocompatibility, especially some are sensitive to environment, such as magnetic field, acidity and heat. Therefore, they have been widely applied in the field of DDS. However, some of them have limitations such as high cost, low encapsulation and uncontrollable dose. Hence, it is very important and challenged to improve the loading capacity, targeted and controlled release properties of the DDS to maximize efficiency of drugs and minimize the cytotoxicity to the normal tissue and cells. In addition, it is also of great importance to optimize the synthetic process to decrease the cost of ceramic-based carriers.

\section{References}

[1] Y. Ji, X.D. Zhang, X.C. Wang, Z.C. Che, X.M. Yu, and H.Z. Yang, Rev. Adv. Mater. Sci., 34 (2013) 72-78.

[2] T.M. Allen and P.R. Cullis, Science, 303 (2004) 1818-1822.

[3] X. Huang, X. Zheng, Z.J. Xu, and C.X. Yi, Int. J. Pharm., 534 (2017) 190-194.

[4] S. Mallakpour and M. Javadpour, Ultrason. Sonochem., 40 (2018) 611-618.

[5] S. Jeon, R. Subbiah, T. Bonaedy, S. Van, S, K. Park, and K. Yun, J. Cell. Physiol., 233 (2018) 1168-1178.

[6] K.S. Soppimath, T.M. Aminabhavi, A.R. Kulkarni, and W.E. Rudzinskib, J. Control. Release, 70 (2001) 1-20.

[7] W. Arap, R. Pasqualini, and E. Ruoslahti, Science, 279 (1998) 377-380. 
[8] V.A. Tran and S.W. Lee, J., Colloid Interface Sci., 510 (2018) 345356.

[9] Q.L. Yang, Y.L. Ma, and J. Zhu, Eur. J. Pharm. Sci., 111 (2018) 383392.

[10] S.C. Thomas, Harshita, P.K. Mishra, and S. Talegaonkar, Curr. Pharm. Design, 21 (2015) 6165-6188.

[11] Z.B. Li, Z.Y. Jiang, L. Zhao, X.R. Yang, J. Zhang, X.J. Song, B. Liu and J.X. Ding, Mater. Sci. Eng. C-Mater. Biol. Appl., 81 (2017) 443-451.

[12] J.C. Zhou, M.A. Frank, Y.Y. Yang, A.R. Boccaccini, and S. Virtanen, Mater. Sci. Eng. C-Mater. Biol. Appl., 82 (2018) 277-283.

[13] M.M. Mehanna, E.N. Abd, and M.W. Samaha, Braz. J. Pharm. Sci., 53 (2017) e16127.

[14] K.E. McNeel, N. Siraj, I. Negulescu, and I.M. Warner, Talanta, 177 (2018) 66-73.

[15] M. Zamani, M. Rostami, M. Aghajanzadeh, H.K. Manjili, K. Rostamizadeh, and H. Danafar, J. Mater. Sci., 53 (2018) 1634-1645.

[16] R.X. Sun, Y. Lv, Y.R. Niu, X.H. Zhao, D.S. Cao, J. Tang, X.C. Sun and K.Z. Chen, Ceram. Int. 43 (2017) 16792-16798.

[17] M.H. Kebiroglu, C. Orek, N. Bulut, O. Kaygili, S. Keser and T. Ates, Ceram. Int., 43 (2017) 15899-15904.

[18] J. Pradid, W. Keawwatana, U. Boonyang, and S. Tangbunsuk, Polym. Bull. 74 (2017) 5181-5194.

[19] J.B. Ran, J.X. Hu, S. Chen, P. Jiang, and X.Y. Shen, Wuhan University Journal of Natural Sciences, 21 (2016) 491-498.

[20] N.A. Arkharova, E.I. Suvorova, A.V. Severin, A.K. Khripunov, S.V. Krasheninnikov, and V.V. Klechkovskaya, Scanning, 38 (2016) 757-765.

[21] Z.Y. Cai, F. Peng, Y.P. Zi, F. Chen, and Q.R. Qian, Nanomaterials, 5 (2015) 1284-1296.

[22] D.Y. Kong, X.L. Xiao, X.Y. Qiu, W.B. Zhang and Y.L. Yang, Chin. J. Chem., 33 (2015) 1024.

[23] C. Shi, J.Y. Gao, M. Wang, J.K. Fu, D.L. Wang and Y.C. Zhu, Mater. Sci. Eng. C-Mater. Biol. Appl., 55 (2015) 497-505.

[24] Y.J. Shyong, M.H. Wang, L.W. Kuo, C.F. Su, W.T. Kuo, K.C. Chang and F.H. Lin, J. Control. Release, 255 (2017) 62-72.

[25] F. Ma, M.F. Cui, J.H. Zhu and Y.L. Li, J. Inorg. Mater., 32 (2017) 1215-1222.

[26] Y.D. Yu, Y.J. Zhu, C. Qi, Y.Y. Jiang, H. Li and J. Wu, J. Colloid Interface Sci., 496 (2017) 416-424.

[27] P.J. Shi, Q. Wang, C.P. Yu, F.J. Fan, M. Liu, M.L. Tu, W.H. Lu, and M. Du, Colloid Surf. B-Biointerfaces, 155 (2017) 477-486.

[28] P. Chitprasert and P. Sutaphanit, J. Agric. Food Chem., 62 (2014) 12641-12648.

[29] S.M. Ryou, J.H. Yeom, H.J. Kang, M. Won, J.S. Kim, B. Lee, M.J. Seong, N.C. Ha, J. Bae, and K. Lee, J. Control. Release, 196 (2014) 287-294.

[30] J. Zhou, B. Zhang, L.J. Shi, J. Zhong, J. Zhu, J. Yan, P. Wang, C.B. Cao, and D.N. He, ACS Appl. Mater. Interfaces, 6 (2014) 2181321821.

[31] C.T. Chen, T. Zhang, Q. Zhang, Z.Q. Feng, C.L. Zhu, Y.L. Yu, K.M. Li, M.Y. Zhao, J.Z. Yang, J. Liu, and D.P. Sun, ACS Appl. Mater. Interfaces, 7 (2015) 28244-28253.

[32] M.T. Dehaghani, M. Ahmadian and B.H. Beni // Mater. Des. 88 (2015) 406.

[33] P. Diaz-Rodriguez, A. Rey-Rico, H. Madry, M. Landin, and M. Cucchiarini, Int. J. Pharm., 496 (2015) 614-626.

[34] N. Lohse, N. Moser, S. Backhaus, T. Annen, M. Epple, and H. Schliephake, J. Control. Release, 220 (2015) 201-209.

[35] W. Qiao, X.M. Lan, J.K.H. Tsoi, Z.F. Chen, R.Y.X. Su, K.W.K. Yeung, and J.P. Matinlinna, RSC Adv. 7 (2017) 44788-44798.
[36] R. Morsy, R. Abuelkhair, and T. Elnimr, Silicon, 9 (2017) 637-641.

[37] Y.J. Shuai, S.X. Yang, C.L. Li, L.J. Zhu, C.B. Mao, and M.Y .Yang, J. Mat. Chem. B, 5 (2017) 3945-3954.

[38] B.C. Simionescu, M. Drobota, D. Timpu, T. Vasiliu, C.A. Constantinescu, D. Rebleanu, M. Calin, and G. David, Mater. Sci. Eng. C-Mater. Biol. Appl., 81 (2017) 167-176.

[39] S.L. Zeng, R.H. Zhou, X.K. Zheng, L. Wu, and X.D. Hou, Microchem J., 134 (2017) 41-48.

[40] H. Li, F. Xue, J. Bai, and C.L. Chu, Mater. Lett., 161 (2015) 455-458.

[41] B.H.B. Kuffner, A.D. Facci, D. Sachs, and G. Silva, REM, Int. Eng. J., 70 (2017) 459-464.

[42] M. Roozbahani, M. Alehosseini, M. Kharaziha, and R. Emadi, Mater. Sci. Eng. C-Mater. Biol. Appl., 81 (2017) 532-541.

[43] R.A. Youness, M.A. Taha, and M.A. Ibrahim, J. Mol. Struct., 1150 (2017) 188-195.

[44] S. Hoover, S. Tarafder, A. Bandyopadhyay, and S. Bose, Mater. Sci. Eng. C-Mater. Biol. Appl., 79 (2017) 763-769.

[45] F. Mirjalili, H. Mohammadi, M. Azimi, M. Hafezi, and N.A.A Osman, Ceram. Int., 43 (2017) 7573-7580.

[46] L.L. Lin, Y.Y. Dong, and Q. Zhou, Sci. Eng. Compos. Mater., 24 (2017) 721-730.

[47] C. Evangelisti, M. Guidotti, C. Tiozzo, R. Psaro, N. Maksimchuk, I. Ivanchikova, A.N. Shmakov, and O. Kholdeeva, Inorg. Chim. Acta, 470 (2018) 393-401.

[48] G. Gonzalez, A. Sagarzazu, A. Cordova, M.E. Gomes, J. Salas, L. Contreras, K. Noris-Suarez, and L. Lascano, Microporous Mesoporous Mat., 256 (2018) 251-265.

[49] S.D. Jiang, G. Tang, J.M. Chen, Z.Q. Huang, and Y. Hu, J. Hazard. Mater., 342 (2018) 689-697.

[50] R.A. Mitran, C. Matei, and D. Berger, J. Phys. Chem. C, 120 (2016) 29202-29209.

[51] T.P. Shao, J. Wen, Q. Zhang, Y.W. Zhou, L. Liu, L.H. Yuwen, Y. Tian, Y.L. Zhang, W. Tian, Y.Y. Su, Z.G. Teng, G.M. Lu, and J. Xu, J. Mater. Chem. B, 4 (2016) 7708-7717.

[52] T.T. Zhao, N. Goswami, J.G. Li, Q.F. Yao, Y. Zhang, J. Wang, D. Zhao and J.P. Xie, Small, 12 (2016) 6537-6541.

[53] M. Bardhan, A. Majumdar, S. Jana, T. Ghosh, U. Pal, S. Swarnakar, and D. Senapati, J. Photochem. Photobiol. B-Biol., 178 (2017) 19.

[54] Y. Yang, Y.Z. Lin, D.H. Di, X. Zhang, D. Wang, Q.F. Zhao, and S.L. Wang, J. Colloid Interface Sci., 508 (2017) 323-341.

[55] J. Zhang, D. Wu, M.F. Li, and J. Feng, ACS Appl. Mater. Interfaces, 7 (2015) 26666-26673.

[56] H.Q. Wang, P.F. Hu, Y. Zheng, Z. Zhao, B. Zheng, J. Chang, H.J. Wang, and J.H. Wang, Mater. Sci. Eng. C-Mater. Biol. Appl., 80 (2017) 102-109.

[57] J.T. Lin, J.K. Du, Y.Q. Yang, L. Li, D.W. Zhang, C.L. Liang, J. Wang, J. Mei, and G.H. Wang, Mater. Sci. Eng. C-Mater. Biol. Appl., 81 (2017) 478-484.

[58] M.Z. Zhang, C.L. Xu, L.Q. Wen, M.K. Han, B. Xiao, J. Zhou, Y.C. Zhang, Z. Zhang, E. Viennois, and D. Merlin, Cancer Res., 76 (2016) 7208-7218.

[59] R.R. Zhu, Z.Q. Wang, P. Liang, X.L. He, X.Z. Zhuang, R.Q. Huang, M. Wang, Q.G. Wang, Y.C. Qian, and S.L. Wang, Acta Biomater., 63 (2017) 163-180.

[60] J.J. Liu, D. Sen Karaman, J.X. Zhang, J.M. Rosenholm, X.M. Guo, and K.Y. Cai, J. Mater. Chem. B, 5 (2017) 8289- 8298.

[61] X.X. Yang, Y. Wen, A.Q. Wu, M.Y. Xu, T. Amano, L.Y. Zheng, and L. Zhao, Mater. Sci. Eng. C-Mater. Biol. Appl. 80 (2017) 517-525.

[62] I.H. Cho, M.K. Shim, B. Jung, E.H. Jang, M.J. Park, H.C. Kang, and J.H. Kim, Microporous Mesoporous Mat., 253 (2017) 96-101. 
[63] X.Q. Jin, Q. Wang, J.H. Sun, H. Panezai, S.Y. Bai and X. Wu // Microporous Mesoporous Mat. 254 (2017) 77.

[64] L. Huang, J. Wu, M.Y. Liu, L.C. Mao, H.Y. Huang, Q. Wan, Y.F. Dai, Y.Q. Wen, X.Y. Zhang, and Y. Wei, J. Colloid Interface Sci., 508 (2017) 396-404.

[65] V. Zelenak, D. Halamova, A. Zelenakova, and V. Girman, J. Porous Mat., 23 (2016) 1633-1645.

[66] W. Wei, Y. Ding, A.K. Zhao, K. Ge, C.M. Zhang, Y.S. Li, J.Y. Zhang and G. Jia, J. Alloy. Compd., 728 (2017) 585-591.

[67] F.Y. Dong, T.T. Zheng, R.R. Zhu, S.L. Wang, and Y. Tian, J. Mater. Chem. B, 4 (2016) 7681-7688.

[68] X.B. Xu, S.Y. Lu, C.M. Gao, X. Bai, C. Feng, N.N. Gao, and M.Z. Liu, Mater. Des., 88 (2015) 1127-1133.

[69] C.M. Zhang, W. Wei, J.Y. Zhang, Y.S. Li, G.Q. Zhou, and G. Jia, Dyes Pigment., 136 (2017) 427-433.

[70] Y.L. Yang, X.L. Yan, X.Y. Hu, R. Feng and M. Zhou, J. Colloid Interface Sci., 505 (2017) 206-212.

[71] P. Adhikari, M. Xiong, N. Li, X. Zhao, P. Rulis, and W.Y. Ching, J. Phys. Chem. C, 120 (2016) 15362-15368.
[72] B. Pattengale, S.Z. Yang, J. Ludwig, Z.Q. Huang, X.Y. Zhang, and J. Huang, J. Am. Chem. Soc., 138 (2016) 8072-8075.

[73] C. Adhikari, A. Das, and A. Chakraborty, Mol. Pharm., 12 (2015) 3158-3166.

[74] S. Li, K. Bi, L. Xiao, and X.W. Shi, Nanotechnology, 28 (2017) 495601.

[75] X.F. Qi, L. Xiong, J. Peng, and D.Y. Tang, RSC Adv., 7 (2017) 1960419610.

[76] K. Bootdee, B.P. Grady, and M. Nithitanakul, Colloid Polym. Sci., 295 (2017) 2031-2040.

[77] Y.M. Yang, F. Xia, Y. Yang, B.Y. Gong, A.J. Xie, Y.H. Shen, and M.Z. Zhu, J. Mater. Chem. B, 5 (2017) 8600.

[78] S. Mortazavi-Derazkola, M. Salavati-Niasari, H. Khojasteh, 0. Amiri, and S.M. Ghoreishi, J. Clean Prod., 168 (2017) 39-50.

[79] D.C. Manatunga, R.M. de Silva, K.M.N. de Silva, N. de Silva, S. Bhandari, Y.K. Yap, and N.P. Costha, Eur. J. Pharm. Biopharm., 117 (2017) 29-38.

[80] S.M.H. Dabiri, A. Lagazzo, F. Barberis, A. Shayganpour, E. Finocchio, and L. Pastorino, Carbohydr. Polym., 177 (2017) 324-333. 